\title{
Highly sensitive determination of dialkyl phosphinate acids in environmental samples by ion chromatography tandem mass spectrometry
}

\author{
Yu-Min Niu ${ }^{\mathrm{a}}$, Yong Liang ${ }^{\mathrm{b}, \mathrm{c}}, \mathrm{Ji}^{-}$Yan Liu ${ }^{\mathrm{b}}$, Jing-Fu Liu ${ }^{\mathrm{a}, *}$ \\ a State Key Laboratory of Environmental Chemistry and Ecotoxicology, Research Center for Eco-Environmental Science, Chinese Academy of Sciences, \\ Beijing 100085, China \\ b School of Medicine, Jianghan University, Hubei Province, Wuhan 430056, China \\ ${ }^{\mathrm{c}}$ Key Laboratory of Optoelectronic Chemical Materials and Devices of Ministry of Education, Jianghan University, Hubei Province, Wuhan 430056, China
}

\section{A R T I C L E I N F O}

\section{Article history:}

Received 29 January 2015

Received in revised form 18 March 2015

Accepted 18 March 2015

Available online 24 March 2015

\section{Keywords:}

Dialkyl phosphinate acids

Solid phase extraction

Environmental water sample

Soil and sediment sample

IC-ESI-MS/MS

\begin{abstract}
A B S T R A C T
Dialkyl phosphinate acids (DPAs) are the hydrolysates of aluminum dialkyl phosphinates (ADPs), one class of emerging phosphorus flame retardants since brominated flame retardants have been gradually phased out in recent years. It has been found that once dissolved in water, ADPs are completely hydrolyzed and exist as DPAs. However, there is no report on the determination of DPAs in environmental water samples. For the first time, we developed a method for the analysis of trace DPAs and ADPs in different environmental samples, including waters, soils and sediments. In this proposed method, MAX cartridges were employed for the purification, and ion chromatography (IC) tandem mass spectrometry (MS) method with large volume injection $(200 \mu \mathrm{L})$ and postcolumn addition of methanol and $\mathrm{NH}_{3} \cdot \mathrm{H}_{2} \mathrm{O}$ were employed for the determination of DPAs and ADPs. The matrix effects were $<16 \%$ for water samples and $<25 \%$ for soil/sediment samples, which were greatly improved in comparison to the liquid chromatography (LC) tandem MS determination. Determined at three fortified levels of $0.02 \mu \mathrm{g} / \mathrm{L}, 0.2 \mu \mathrm{g} / \mathrm{L}$ and $1.0 \mu \mathrm{g} / \mathrm{L}$, the mean recoveries were from $75.8 \%$ to $110.2 \%$, with an acceptable coefficient of variation $(3.3-20 \%, n=6)$ for water samples. The limits of the method were 3.5-9.3 ng/L for DPAs in environmental water samples, and $0.06-0.09 \mu \mathrm{g} / \mathrm{kg}$ for DPAs and ADPs in soil and sediment samples. For soil and sediment samples, results determined by the present IC-MS method were in good agreement with that determined by LC-MS in our previous study.
\end{abstract}

(c) 2015 Elsevier B.V. All rights reserved.

\section{Introduction}

Aluminum dialkyl phosphinates (ADPs, aluminum salts of phosphinic acid having alkyl and/or aryl substitutes) are a class of the most promising flame retardants used as substitute of brominated flame retardants (BFRs) which have been gradually phased out in the United States (US) and European Union (EU) in recent years [1-5]. ADPs have already been widely used in the electrical and electronic equipments, connectors, switches, and encapsulated electronic components in many countries, including China [6]. Due to this activity, it is estimated that up to $165 \mathrm{~kg}$ per annum of aluminum salts of diethylphosphinic (ADEP) could be disposed to landfill according to authority statistics [7].

\footnotetext{
* Corresponding author. Tel.: +86 10 62849192; fax: +861062849192.

E-mail address: jfliu@rcees.ac.cn (J.-F. Liu).
}

Accompanying with the production and application, ADPs will inevitably be introduced into the human living environments [5], like other organophosphate esters flame retardants. In our previous study, three kinds of ADPs, including aluminum salts of methylethylphosphinic (AMEP) and methylcyclohexyl phosphinic (AMHP) and ADEP have been found in soil and sediment samples. At the same time, the hydrolysates of ADPs (dialkyl phosphinate acids, DPAs) have also been found, and both ADPs and DPAs showed relatively high vertical mobility in soil and sediment [8]. Although it was speculated that ADEP was unlikely leached into the water compartment due to its low solubility [7,9], the high hydrophilicity of DPAs indicating ADPs could potentially contaminate groundwater in the form of DPAs by leaching from soils and sediments [10]. Moreover, we have demonstrated that once dissolved in water, the O-Al covalent bonds in ADPs would be broken, thereafter ADPs hydrolyzed to DPAs [8]. Therefore, it is speculated that ADPs would present in environmental water samples in the form of DPAs. For example, the direct discharge of ADPs in manufacture plant and the 
diffusion from the flame retardant products could bring the risk of contamination of wastewater by DPAs. Subsequently, DPAs could be introduced into surface water via waste water treatment plant (WWTP).

As the 72-h no observed effect concentration (NOEC) based on algae was $2.2 \mathrm{mg} / \mathrm{L}$ for ADEP, a predicted no effect concentration for aquatic organisms of $44 \mu \mathrm{g} / \mathrm{L}$ was given by National Industrial Chemicals Notification and Assessment Scheme (NICNAS) [9]. In addition, Waaijers et al. reported that ADEP could affect the sublethal life cycle parameters of daphnid for chronic exposure, such as cumulative reproductive output and population growth rate [11]. Given the fact that ADPs were hydrolyzed to DPAs once dissolved in water [8], the reported negative effects on the aquatics mentioned above should be caused by DPAs.

Considering the potential toxicity of ADPs to aquatic organisms and the possibility of DPAs existing in environmental water samples, an overall investigation on the occurrence and the environmental behavior of ADPs and DPAs is urgently needed. However, a bottleneck of this work is the absence of sufficiently sensitive analytical procedure for the determination of DPAs in environmental water samples at trace levels. ADPE in the exposure solutions has been determined by inductively coupled plasma-atomic emission spectroscopy (ICP-AES) through determining phosphorus [11], or by measuring $\mathrm{Al}^{3+}$ through complexation with Alizarinred [7]. However, these two methods are not appropriate for the determination of ADPs and DPAs in environmental water because of the ingenerate of phosphorus and $\mathrm{Al}^{3+}$ in water samples.

In this study, a novel analytical method based on solid phase extraction (SPE) and ion chromatography (IC) tandem mass spectrometry (MS) method was developed. Three DPAs including methylethylphosphinic acid (MEPA), diethylphosphinic acid (DEPA) and methylcyclohexyl phosphinic acid (MHPA) in water samples were extracted by SPE, and injected into the IC-MS system with large volume injection for highly sensitive detection. This method was applied to determine DPAs in four different environmental waters, including tap water, river water, influent and effluent water of WWTP with satisfactory results. In addition, the IC-MS method was also appropriate for the determination of DPAs and ADPs in soil and sediment samples.

\section{Materials and methods}

\subsection{Chemicals and reagents}

AMEP, ADEP and AMHP with purity >95\% were provided by Jianghan University (Hubei province, China). MEPA and DEPA with the purity $>95 \%$, and MHPA with the purity $>90 \%$ were synthesized from AMEP, ADEP and AMHP individually in our laboratory, according to the reported methods [8]. HPLC grade methanol was supplied by Fisher Scientific (Fair Lawn, NJ). Formic acid with 99\% purity was purchased from Acros Organics (Morris Plains, NJ). Ammonium hydroxide $\left(\mathrm{NH}_{3} \cdot \mathrm{H}_{2} \mathrm{O}, 15 \mathrm{M}\right)$ was obtained from Sinopharm Chemical Reagent Co. (Beijing, China). Ultra-pure water produced with a Milli-Q Gradient system (Millipore, Bedford, USA) was used throughout the experiment.

Individual DPA stock solutions $(1000 \mathrm{mg} / \mathrm{L})$ were prepared by dissolving an appropriate amount of each substance in methanol and storing at $-20^{\circ} \mathrm{C}$ in amber glass vessels. Working standard mixtures were prepared by combining the stock solutions and diluting with ultra-pure water before immediate use.

\subsection{Sample preparation}

On the arrival in the laboratory, all water samples were filtered through GF/A glass fiber membrane filters $(1.2 \mu \mathrm{m}$; Whatman,
Maidstone, UK) and immediately analyzed. Aliquot of $7 \mathrm{~mL}$ water samples with $\mathrm{pH}$ 5-9 were applied to a lipophilic exchanger mixedmode sorbent (MAX) cartridge ( $6 \mathrm{~mL}, 500 \mathrm{mg}$, Waters, Milford, MA, USA). The cartridges were conditioned sequentially with $6 \mathrm{~mL}$ of methanol and $6 \mathrm{~mL}$ of ultra-pure water prior to use. Water samples were passed through the cartridges under gravity. After samples loading, the SPE cartridges were dried under vacuum aspiration for $2 \mathrm{~h}$. Then the analytes were eluted by $5 \mathrm{~mL}$ methanol with $2 \%$ formic acid. The eluates were evaporated to dryness by a gentle nitrogen stream under $40^{\circ} \mathrm{C}$ and finally made up to $1.0 \mathrm{~mL}$ with ultra-pure water for IC-MS/MS analysis.

For soil and sediment samples, the pretreatment procedure was exactly the same as our previous study [8], except for the finally dilution solution. In brief, $0.5 \mathrm{~g}$ of samples were weighed in duplicate, and extracted by $2.5 \mathrm{~mL}$ aqueous solutions of $75 \mathrm{mM} \mathrm{NH}_{3} \cdot \mathrm{H}_{2} \mathrm{O}$ and formic acid-water-methanol (5:5:90, v/v/v) respectively. The supernatants were cleaned up by MAX cartridges and eluted by $5 \mathrm{~mL} 2 \%$ formic acid in methanol. The eluates were evaporated to dryness and finally made up to $1.0 \mathrm{~mL}$ with ultra-pure water for IC-MS/MS analysis.

\subsection{Instrument analysis}

The chromatographic separation was carried out on a Dionex ICS-3000 Regent-Free ${ }^{\mathrm{TM}}$ Ion Chromatography (Thermofisher, Sunnyvale, CA, USA), consisting of an autosampler (AS), a dual pump unit (DP), an eluent generator unit (EG) and a column and detector compartment (DC). A $2 \mathrm{~mm} \times 250 \mathrm{~mm}$ IonPac ${ }^{\circledR}$ AS11-HC weak anion-exchange analytical column protected by its guard column, AG11-HC ( $2 \mathrm{~mm} \times 50 \mathrm{~mm})$, was employed as the separation column. The injection volume was set at $200 \mu \mathrm{L}$ and the column temperature was set at $30^{\circ} \mathrm{C}$. Potassium hydroxide solution generated by the EG was used as the eluent. With a flow rate of $0.3 \mathrm{~mL} / \mathrm{min}$, the gradient elution was operated with $5 \mathrm{mM}$ potassium hydroxide held for $2 \mathrm{~min}$, followed by a 5 -min linear gradient to $10 \mathrm{mM}$, then a further $8 \mathrm{~min}$ to $30 \mathrm{mM}$, and finally kept for $5 \mathrm{~min}$. The suppression of column effluent was accomplished with an anion self-regenerating suppressor (ASRS ULTRA II, $2 \mathrm{~mm}$ ) in the external water mode at $30 \mathrm{~mA}$. A T-fitting was inserted between the electrical conductivity detector and MS detector. Through the Tfitting, the eluent and $0.1 \mathrm{~mL} / \mathrm{min}$ methanol with $45 \mathrm{mM} \mathrm{NH} \mathrm{H}_{3} \cdot \mathrm{H}_{2} \mathrm{O}$ delivered with a ACQUITY Waters Pump (Waters, Mildord, MA, USA) were mixed, and then interfaced with an electrospray probe (ESI) of a triple quadrupole MS (TSQ Quantum Access, Thermo Fisher Scientific, San Jose, CA, USA).

MS/MS acquisition was conducted in the negative ion mode which has been described in our previous study [8], and from which the only difference was that ion sweep gas set at 3 (in arbitrary units) was used to decrease the interference with matrices.

\subsection{Method validation}

To evaluate the performance of the established method for the analysis of DPAs in environmental water samples, quality parameters such as matrix effects, linearity, sensitivity, accuracy and precision were studied in four different water samples (tap water, river water, influent and effluent water of WWTP). The assessment of matrix effects is critical since isotope labeled standards are unavailable for the target compounds [12]. It was evaluated by preparing a neat standard curve and a matrix-matched standard curve, plotted by using standards spiked in ultra-pure water and in extracts of blank environmental water samples before IC-MS/MS analysis, respectively. The ratio between the slope of matrixmatched standard curve and neat standard curve multiplied and subtracted by 100 was identified as the matrix effects [12]. The sensitivity of the method was evaluated by the limit of determination 

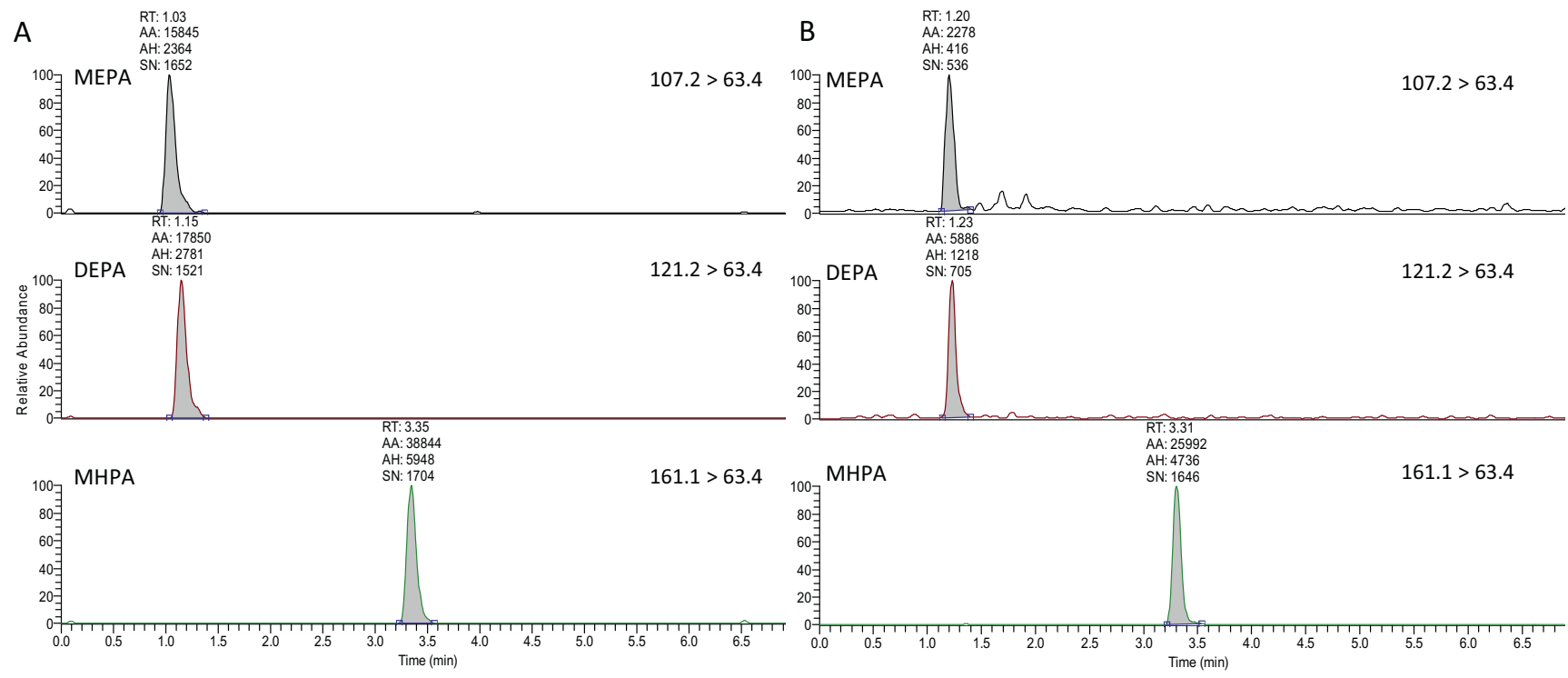

C
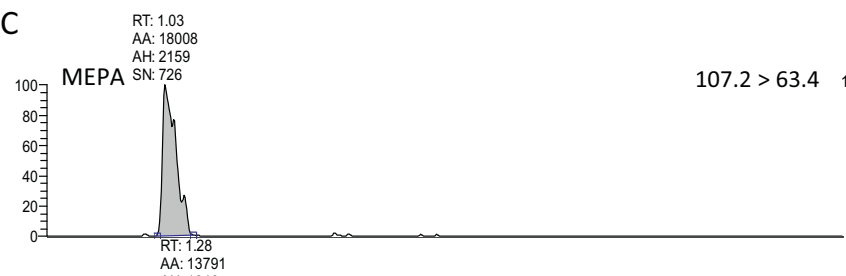

D
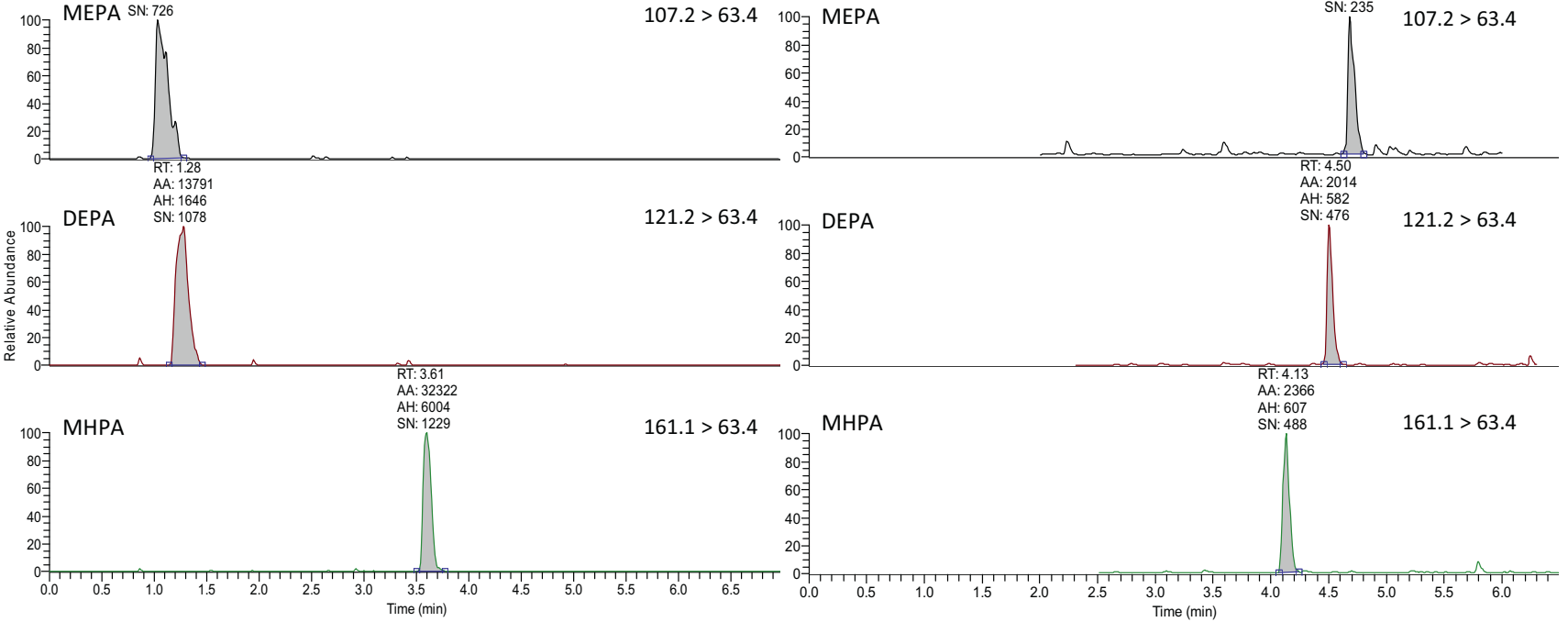

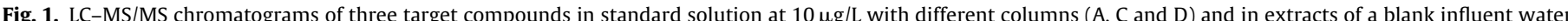

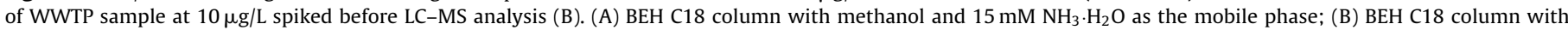

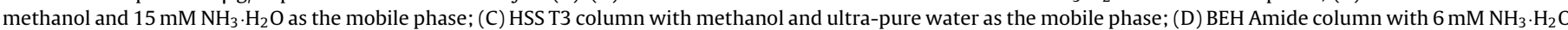
in acetonitrile:methanol $(3: 1, \mathrm{v} / \mathrm{v})$ and $10 \mathrm{mM}$ ammonium acetate as the mobile phase.
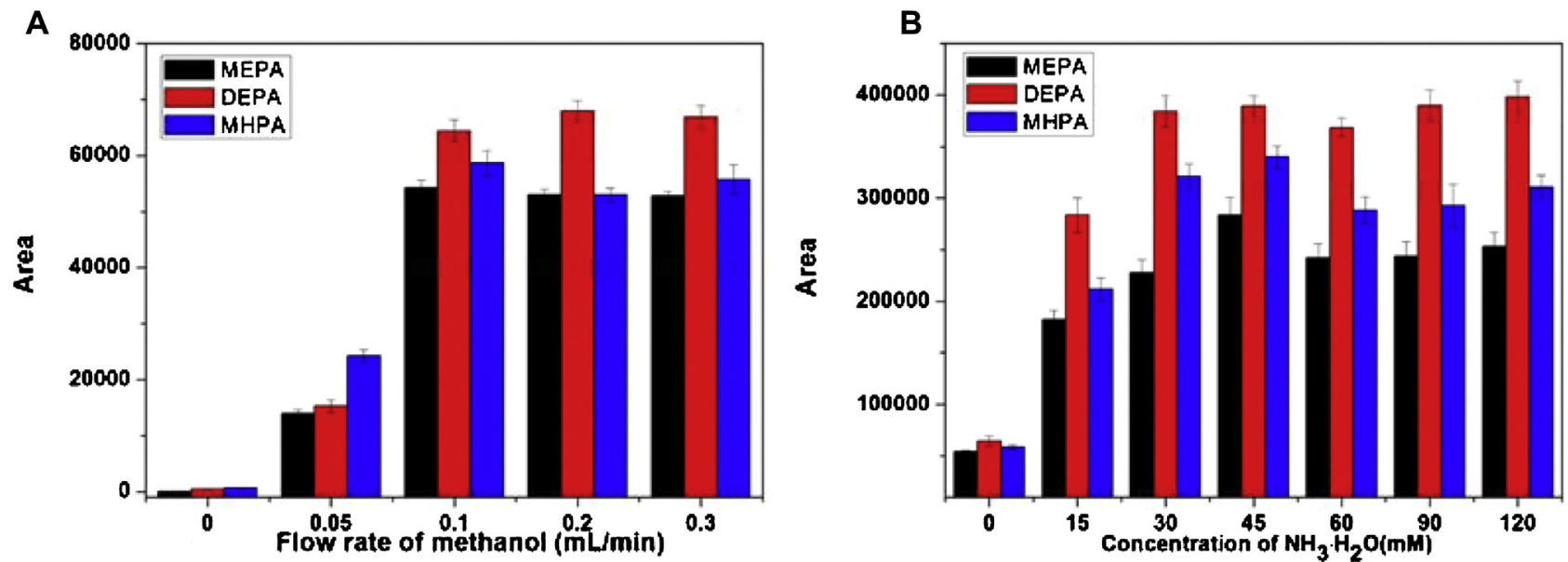

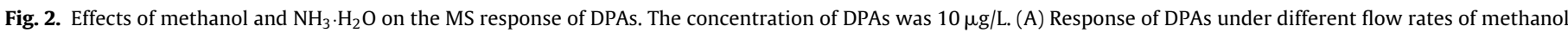

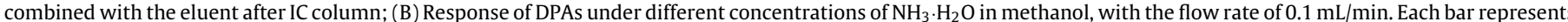
the mean values \pm standard deviation for six replicates. 


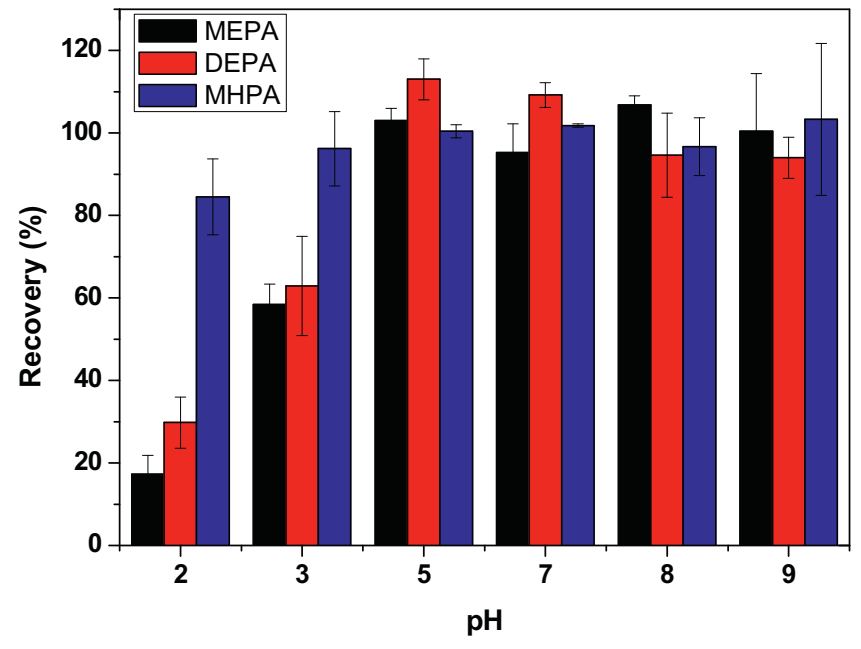

Fig. 3. Effect of $\mathrm{pH}$ on the recovery of DPAs in influent water of WWTP. Blank influent water sample was adjusted to desired $\mathrm{pH}$ values with $\mathrm{NH}_{3} \cdot \mathrm{H}_{2} \mathrm{O}$ and formic acid, then $5 \mathrm{~mL}$ of the influent water spiked with $1 \mathrm{ng}$ each of DPAs and loaded on the MAX cartridges. Each bar represents the mean values \pm standard deviation for six replicates.

(LOD) and limit of quantification (LOQ), which represented the lowest spiked concentration that can yield a signal-to-noise ratio $(S / N)$ greater than 3 and 10 in the selected production chromatogram, respectively. Linearity of the method was evaluated by a matrixfortified calibration curve plotted by using the standards spiked in blank water samples before pretreatment. It was started from a concentration value upper to LOQ for all the three DPAs. Both recovery and precision were evaluated by spiking blank environmental water samples with DPAs at $0.02,0.2$ and $1.0 \mu \mathrm{g} / \mathrm{L}$ in six replicates.

Since the pretreatment procedure of soil and sediment was the same with our previous study, the performance of IC-MS was evaluated only by the matrix effects, linearity and sensitives. The parameters of ADPs in soil and sediment were calculated by that of DPAs.

Carryover was evaluated by injecting influent water extracts spiked with $20 \mu \mathrm{g} / \mathrm{L}$ of each of the analytes in six samples, following by two reagent blank samples to detect the presence of the target chemicals. The peak areas of the first blank samples were divided by that of the standard at high concentration to get a quantitative evaluation of carryover [13].

\section{Results and discussion}

\subsection{Optimization of the chromatographic separation}

In our previous study, liquid chromatogram (LC) separation coupled with MS detection was employed for the determination of trace DPAs in soils and sediments [8]. However, as shown in Fig. $1 \mathrm{~A}$ and $\mathrm{B}$, significant matrix effects were observed for MEPA $(\sim 85 \%)$ and DEPA ( $\sim 60 \%)$ in influent water of WWTP, which were higher than that observed in soil and sediment samples ( $\sim 34 \%$ and $\sim 14 \%$, respectively) [8]. It should be ascribed to two reasons. First, the amount of soil and sediment samples was $0.5 \mathrm{~g}$, whereas the amount of water samples was $7 \mathrm{~mL}$. The matrix effects increased with the sample amount. In addition, signal suppression within the ionization interface was caused by the insufficient separation of the target analytes from matrix components [14,15]. Since solvent extraction method was used, substances only dissoluble in extraction solvents could be extracted from soil and sediment samples. There were more aqueous interferents in influent water than in the soil and sediment extracts. In addition to the weak retention of MEPA and DEPA (retention time of $1.03 \mathrm{~min}$ and $1.15 \mathrm{~min}$, respectively, Fig. 1A) in reversed phase chromatography, the signal suppression in influent water was more significant than that in soil and sediment samples. Therefore, an effective means of improving the matrix effect is by increasing the retention of target compounds in separation. Although the retention capacity could be improved by the addition of formic acid in mobile phase $(2.77 \mathrm{~min}$ and 3.96 min, respectively), a significant reduction of responses of target compounds (2-80 times) were observed at the same time. Formic acid in mobile phase inhibits the ionization of DPAs. It is reported that the ACQUITY UPLC HSS T3 column $(2.1 \mathrm{~mm} \times 100 \mathrm{~mm}$, particle size, $1.8 \mu \mathrm{m}$, Waters, Milford, MA, USA) with high strength silica particles is suitable for retaining and separating polar compounds $[16,17]$. However, the retention behaviors of MEPA and DEPA were not improved by this column comparing with $\mathrm{C} 18$ (Fig. 1C). Hydrophilic interaction liquid chromatography (HILIC) is an interesting tool for the analysis of polar compounds which are difficult to be retained in conventional reversed phase systems [18]. Here the HILIC separation was performed on BEH Amide column

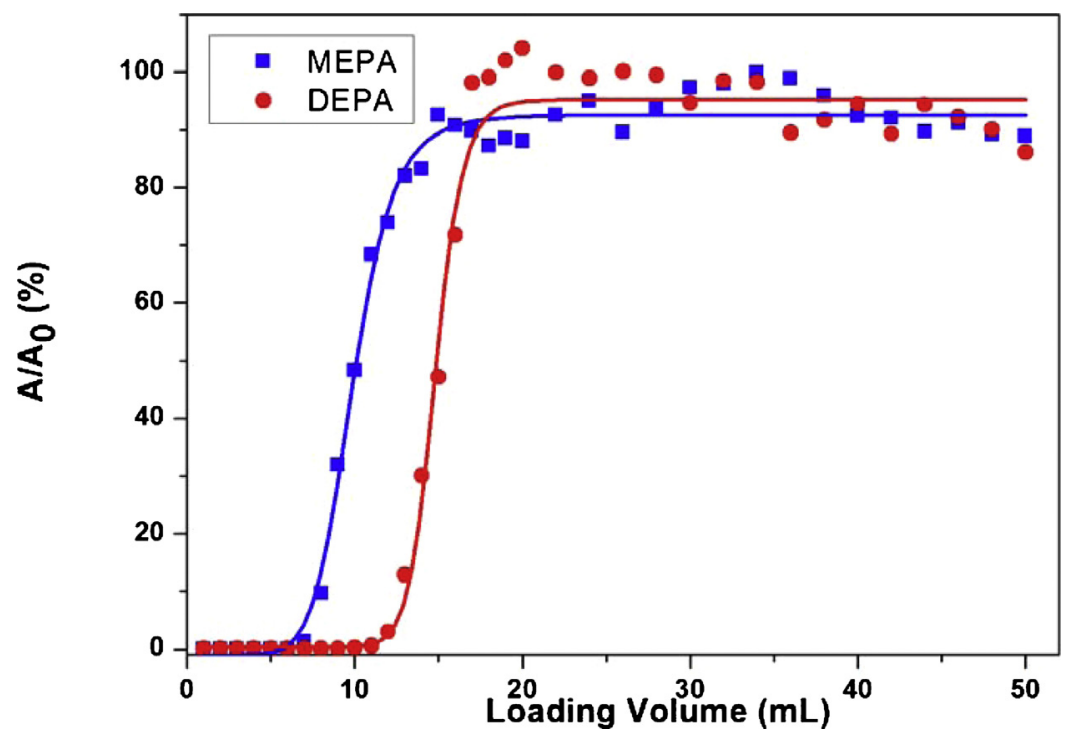

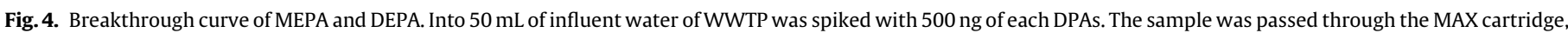
and the eluent was collected in $1 \mathrm{~mL}$ fraction vials. 
A

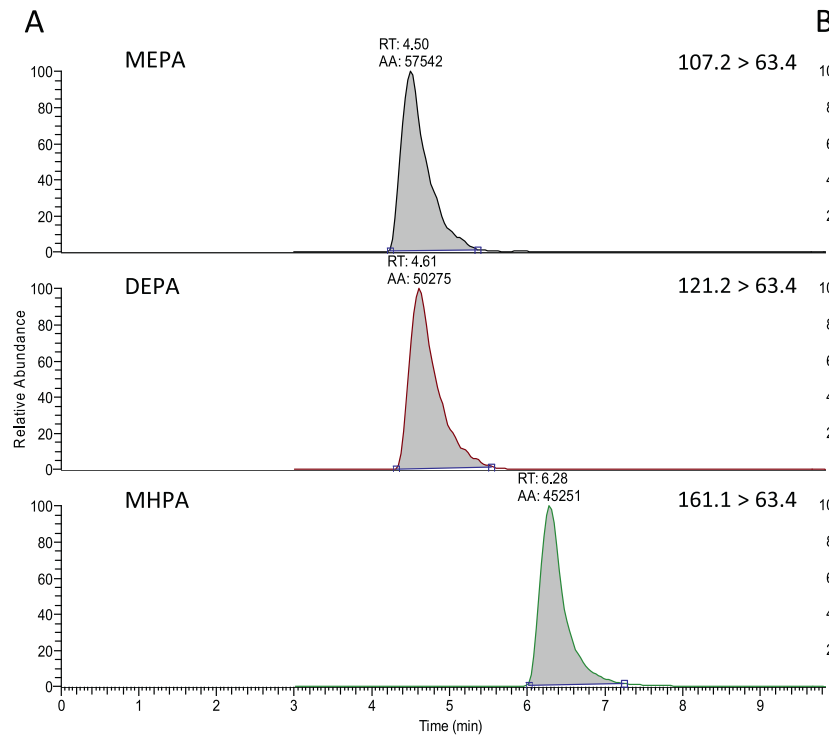

B

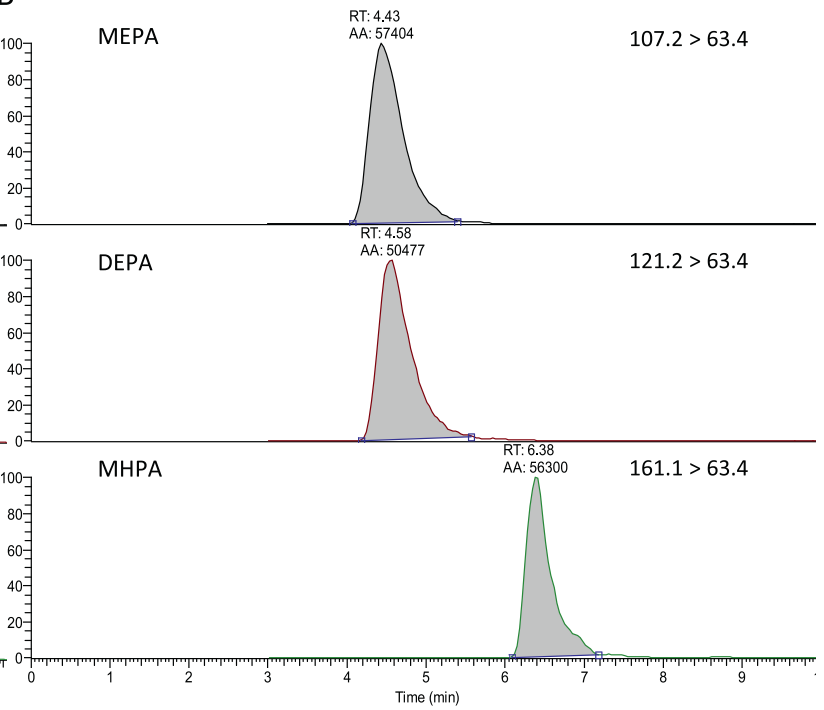

C
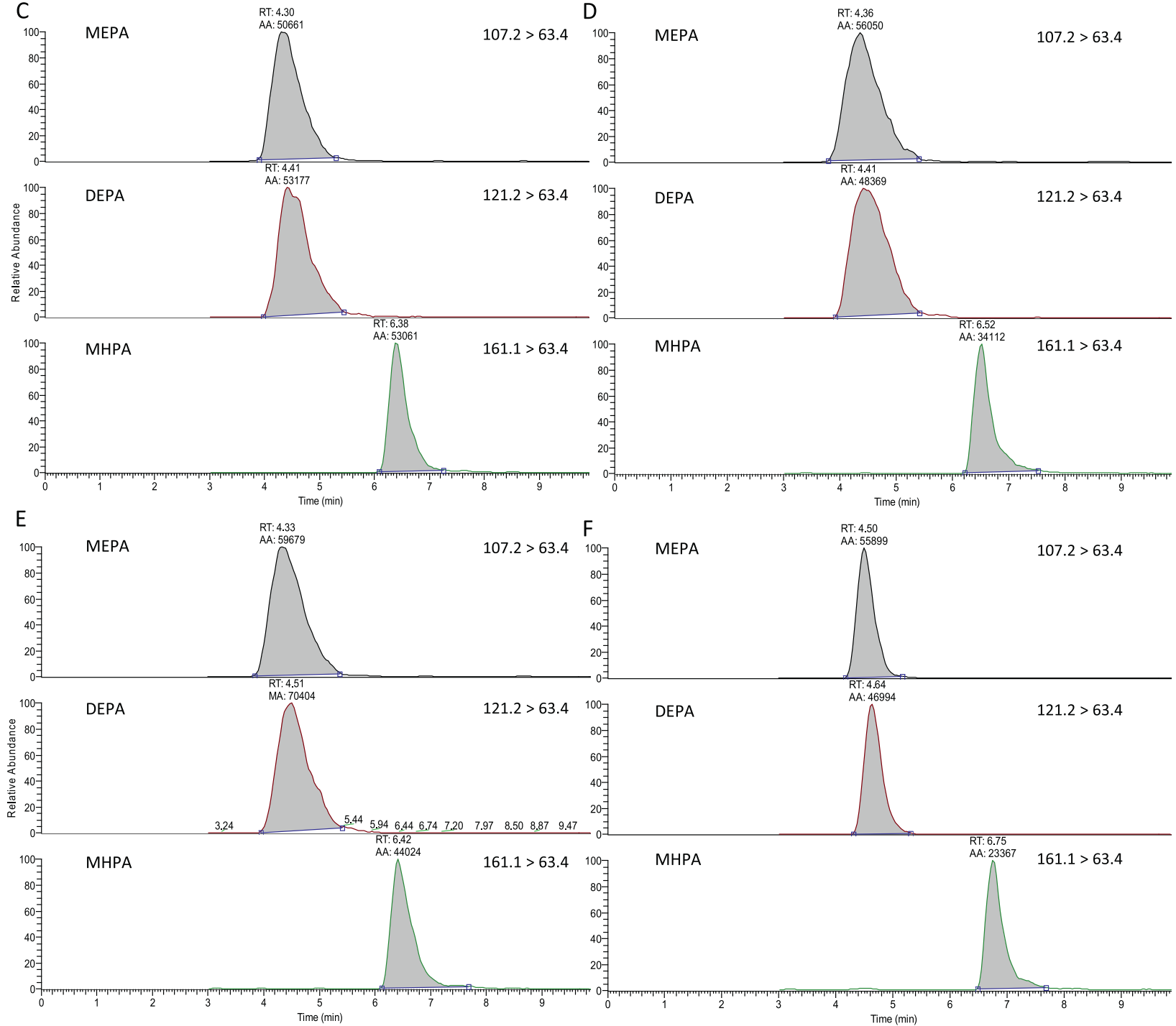

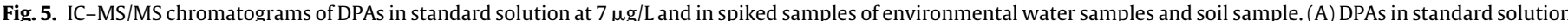

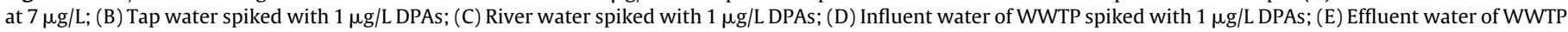
spiked with $1 \mu \mathrm{g} / \mathrm{L}$ DPAs; (F) Soil sample spiked with $14 \mu \mathrm{g} / \mathrm{kg}$ DPAs, and extracted by $75 \mathrm{mM} \mathrm{NH}_{3} \cdot \mathrm{H}_{2} \mathrm{O}$. 
Table 1

Analytical performance of the IC-MS/MS method for water samples.

\begin{tabular}{|c|c|c|c|c|c|c|c|c|c|}
\hline \multirow[t]{2}{*}{ Water sample } & \multirow[t]{2}{*}{ Compound } & \multirow[t]{2}{*}{ Linear range $(\mu \mathrm{g} / \mathrm{L})^{\mathrm{a}}$} & \multirow[t]{2}{*}{$R^{2 \mathrm{a}}$} & \multirow[t]{2}{*}{$\operatorname{LOQ}(\mathrm{ng} / \mathrm{L})^{\mathrm{a}}$} & \multirow[t]{2}{*}{$\operatorname{LOD}(\mathrm{ng} / \mathrm{L})^{\mathrm{a}}$} & \multicolumn{3}{|c|}{ Slope of standard curve } & \multirow[t]{2}{*}{ Matrix effect ${ }^{\mathrm{b}}(\%)$} \\
\hline & & & & & & Neat & Matrix-matched & Matrix-fortified & \\
\hline \multirow{3}{*}{ Tap water } & MEPA & $0.01-20.0$ & 0.9999 & 5.1 & 1.7 & 8149.6 & 8039.5 & 7346.8 & 1.4 \\
\hline & DEPA & $0.01-20.0$ & 0.9927 & 3.9 & 1.3 & $10,805.1$ & $10,563.0$ & $11,097.4$ & 2.2 \\
\hline & MHPA & $0.01-20.0$ & 0.9999 & 4.1 & 1.4 & 7292.1 & 7874.2 & 6799.4 & -8.0 \\
\hline \multirow{3}{*}{ River water } & MEPA & $0.01-20.0$ & 0.9938 & 9.3 & 3.1 & 8149.6 & 7746.3 & 8032.6 & 4.9 \\
\hline & DEPA & $0.01-20.0$ & 0.9967 & 6.3 & 2.1 & $10,805.1$ & $10,739.1$ & $11,055.9$ & 0.6 \\
\hline & MHPA & $0.01-20.0$ & 0.9945 & 4.4 & 1.5 & 7292.1 & 7647.7 & 6733.2 & -4.9 \\
\hline \multirow{3}{*}{ Effluent water } & MEPA & $0.01-20.0$ & 0.9987 & 7.0 & 2.3 & 8149.6 & 8148.6 & 8652.6 & 0.0 \\
\hline & DEPA & $0.01-20.0$ & 0.9909 & 4.3 & 1.4 & $10,805.1$ & $11,066.4$ & 9978.1 & -2.4 \\
\hline & MHPA & $0.01-20.0$ & 0.9946 & 3.5 & 1.2 & 7292.1 & 7427.1 & 6973.8 & -1.9 \\
\hline \multirow{3}{*}{ Influent water } & MEPA & $0.01-20.0$ & 0.9957 & 8.1 & 2.7 & 8149.6 & 8616.7 & 8036.2 & -5.7 \\
\hline & DEPA & $0.01-20.0$ & 0.9991 & 4.1 & 1.4 & $10,805.1$ & $12,055.2$ & $11,078.2$ & -11.6 \\
\hline & MHPA & $0.01-20.0$ & 0.9955 & 3.6 & 1.2 & 7292.1 & 8394.1 & 7083.8 & -15.1 \\
\hline
\end{tabular}

a Linearity range, $R^{2}$ and LOQ were obtained from the matrix-fortified standard curves, which were used for quantitative determinations.

b Calculated as [1 - (the slope of matrix-matched standard curves/the slope of neat standard curves)] $\times 100 \%$.

(2.1 mm × $50 \mathrm{~mm}$; particle size, $1.7 \mu \mathrm{m}$, Waters, Milford, MA, USA). The target compounds demonstrated typical behavior on Amide stationary phase (Fig. 1D). However, the observed $S / N$ ratios were 3-7 times lower than that obtained by BEH C18. Considering the sensitivity of the method, BEH Amide was not appropriate for the detection of DPAs in water samples.

To improve the retention behaviors of MEPA and DEPA, coupling of IC with MS was employed for it has been successfully used for the determination of some polar organic micropollutants in water samples [19-21]. Having composed of divinylbenzene/ ethylvinylbenzene polymer coated with microporous substrate particles with hydroxyalkyl quaternary ammonium functional groups, AS11-HC column has a high capacity of $290 \mu$ equiv., which allows the separation of various anions with large volume injection without overloading and peak broadening [22]. Therefore, AS11-HC column was selected as the separation column in this experiment. It is reported that the sensitivity can be increased by introducing an organic modifier to enhance the ionization process during ESI [23-26]. Therefore, the flow rate of methanol with a post-column addition was optimized. As shown in Fig. 2A, the responses of DPAs

Table 2

Recoveries of DPAs in environmental water samples $(n=6)$.

\begin{tabular}{|c|c|c|c|c|}
\hline Water sample & Compounds & Spiked level $(\mu \mathrm{g} / \mathrm{L})$ & Recovery (\%) & RSD (\%) \\
\hline \multirow{9}{*}{ Tap water } & \multirow{4}{*}{ MEPA } & 0.02 & 90.0 & 6.5 \\
\hline & & 0.2 & 91.4 & 10 \\
\hline & & 1.0 & 103.8 & 6.9 \\
\hline & & 0.02 & 80.9 & 13 \\
\hline & \multirow[t]{2}{*}{ DEPA } & 0.2 & 105.1 & 7.9 \\
\hline & & 1.0 & 98.8 & 3.3 \\
\hline & \multirow{3}{*}{ MHPA } & 0.02 & 75.8 & 20 \\
\hline & & 0.2 & 86.4 & 12 \\
\hline & & 1.0 & 90.3 & 8.8 \\
\hline \multirow{9}{*}{ River water } & \multirow{4}{*}{ MEPA } & 0.02 & 88.9 & 10 \\
\hline & & 0.2 & 103.7 & 7.3 \\
\hline & & 1.0 & 110.2 & 8.1 \\
\hline & & 0.02 & 81.3 & 16 \\
\hline & \multirow[t]{2}{*}{ DEPA } & 0.2 & 102.9 & 15 \\
\hline & & 1.0 & 96.8 & 7.9 \\
\hline & \multirow{3}{*}{ MHPA } & 0.02 & 81.5 & 22 \\
\hline & & 0.2 & 88.0 & 17 \\
\hline & & 1.0 & 106.2 & 6.9 \\
\hline \multirow{9}{*}{ Effluent water } & \multirow{4}{*}{ MEPA } & 0.02 & 79.2 & 7.7 \\
\hline & & 0.2 & 106.2 & 11 \\
\hline & & 1.0 & 98.7 & 2.7 \\
\hline & & 0.02 & 94.7 & 12 \\
\hline & \multirow[t]{2}{*}{ DEPA } & 0.2 & 90.2 & 9.5 \\
\hline & & 1.0 & 104.8 & 2.8 \\
\hline & \multirow{3}{*}{ MHPA } & 0.02 & 97.5 & 12 \\
\hline & & 0.2 & 93.9 & 6.9 \\
\hline & & 1.0 & 100.8 & 4.0 \\
\hline \multirow{9}{*}{ Influent water } & \multirow{4}{*}{ MEPA } & 0.02 & 86.2 & 14 \\
\hline & & 0.2 & 93.3 & 16 \\
\hline & & 1.0 & 109.8 & 3.4 \\
\hline & & 0.02 & 76.7 & 3.4 \\
\hline & \multirow[t]{2}{*}{ DEPA } & 0.2 & 94.6 & 7.9 \\
\hline & & 1.0 & 112.7 & 10 \\
\hline & \multirow{3}{*}{ MHPA } & 0.02 & 86.7 & 8.2 \\
\hline & & 0.2 & 90.4 & 3.7 \\
\hline & & 1.0 & 88.9 & 5.9 \\
\hline
\end{tabular}


Table 3

Comparison of the analytical performance of the IC-MS and LC-MS method for soil and sediment samples.

\begin{tabular}{|c|c|c|c|c|c|c|c|c|c|}
\hline \multirow[t]{2}{*}{ Extraction solvent } & \multirow[t]{2}{*}{ Compound } & \multicolumn{2}{|c|}{ Linear range $(\mu \mathrm{g} / \mathrm{kg})^{\mathrm{a}}$} & \multicolumn{2}{|c|}{$\mathrm{LOQ}(\mu \mathrm{g} / \mathrm{kg})^{\mathrm{a}}$} & \multicolumn{2}{|c|}{$\operatorname{LOD}(\mu \mathrm{g} / \mathrm{kg})^{\mathrm{a}}$} & \multicolumn{2}{|c|}{ Matrix effect ${ }^{\mathrm{b}}(\%)$} \\
\hline & & IC-MS & LC-MS & IC-MS & LC-MS & IC-MS & LC-MS & IC-MS & LC-MS \\
\hline \multirow{6}{*}{$\begin{array}{l}75 \mathrm{mM} \\
\mathrm{NH}_{3} \cdot \mathrm{H}_{2} \mathrm{O}\end{array}$} & MEPA & $0.10-200.0$ & $0.92-921.7$ & 0.07 & 0.92 & 0.02 & 0.31 & -4.2 & 34.3 \\
\hline & DEPA & $0.10-200.0$ & $0.93-930.7$ & 0.07 & 0.93 & 0.02 & 0.31 & 4 & 13.9 \\
\hline & MHPA & $0.10-200.0$ & $0.95-947.1$ & 0.09 & 0.95 & 0.03 & 0.32 & 24.6 & 6.6 \\
\hline & AMEP & $0.11-217.4$ & $1.0-1000.0$ & 0.08 & 1.0 & 0.03 & 0.33 & -4.2 & 35.7 \\
\hline & ADEP & $0.11-215.1$ & $1.0-1000.0$ & 0.08 & 1.0 & 0.03 & 0.33 & 4 & 10.1 \\
\hline & AMHP & $0.11-210.5$ & $1.0-1000.0$ & 0.09 & 1.0 & 0.03 & 0.33 & 24.6 & 5.2 \\
\hline \multirow{3}{*}{$\begin{array}{l}\text { Formic } \\
\text { acid-water-methanol } \\
(5: 5: 90, v / v / v)\end{array}$} & MEPA & $0.10-200.0$ & $0.92-921.7$ & 0.06 & 0.92 & 0.02 & 0.31 & 1.8 & 45.9 \\
\hline & DEPA & $0.10-200.0$ & $0.93-930.7$ & 0.06 & 0.93 & 0.02 & 0.31 & 8.3 & -4.3 \\
\hline & MHPA & $0.10-200.0$ & $0.95-947.1$ & 0.07 & 0.95 & 0.02 & 0.32 & 10.6 & -4.7 \\
\hline
\end{tabular}

a Linearity range, $R^{2}$ and LOQ were obtained from the matrix-matched standard curves, which were used for quantitative determinations in this study.

b Calculated as [1 - (the slope of matrix-matched standard curves/the slope of neat standard curves)] $\times 100 \%$.

were increased with the flow rate in the range of $0-0.1 \mathrm{~mL} / \mathrm{min}$, and then leveled off in the range of $0.1-0.3 \mathrm{~mL} / \mathrm{min}$. Therefore, $0.1 \mathrm{~mL} / \mathrm{min}$ of methanol was finally chosen. As explained by Kostiainen and Kauppila, high viscosity of water lead to inefficient charge separation and difficulties in producing a stable spay, and the addition of organic solvents could improve the charge separation and spray formation [23]. Since the addition of $\mathrm{NH}_{3} \cdot \mathrm{H}_{2} \mathrm{O}$ could also promote the ionization of DPAs, the concentration of $\mathrm{NH}_{3} \cdot \mathrm{H}_{2} \mathrm{O}$ in methanol was optimized to further increase the sensitivity. It can be seen from Fig. $2 \mathrm{~B}$ that $45 \mathrm{mM} \mathrm{NH}_{3} \cdot \mathrm{H}_{2} \mathrm{O}$ in methanol was enough to promote the ionization of DPAs for the ESI process.

\subsection{Sample pretreatment}

If environmental water samples were directly injected into the IC-MS/MS system, the non-volatile inorganic anion could be eluted from the AS11-HC column and then introduced into the ESI spray, blocking the capillary and interferencing the ionization of the target compounds. As a well-established fast, straightforward and easily automated method for cleaning and pre-concentrating samples from diverse matrices, SPE was adopted in this study as the extraction and preconcentration tool. Optimization of the extraction and preconcentration conditions was performed with influent water of WWTP because of its complexity. MAX cartridge,

Table 4

Analytes concentration and spike recovery (mean $\pm \mathrm{SD}, \%, n=3$ ) in environmental water samples by the proposed method.

\begin{tabular}{|c|c|c|c|c|c|c|c|}
\hline \multirow[t]{2}{*}{ Water samples } & \multirow[t]{2}{*}{ Spiked $(\mu \mathrm{g} / \mathrm{L})$} & \multicolumn{2}{|l|}{ MEPA } & \multicolumn{2}{|l|}{ DEPA } & \multicolumn{2}{|l|}{ MHPA } \\
\hline & & Detected $(\mu \mathrm{g} / \mathrm{L})$ & Recovery (\%) & Detected ( $\mu \mathrm{g} / \mathrm{L})$ & Recovery (\%) & Detected $(\mu \mathrm{g} / \mathrm{L})$ & Recovery (\%) \\
\hline \multicolumn{8}{|l|}{ Tap water } \\
\hline \multirow[t]{2}{*}{1} & 0 & $\mathrm{nd}^{\mathrm{a}}$ & nd & nd & nd & nd & nd \\
\hline & 0.5 & $0.50 \pm 0.08$ & $100 \pm 16$ & $0.45 \pm 0.04$ & $90.3 \pm 8.3$ & $0.58 \pm 0.04$ & $116 \pm 8.1$ \\
\hline \multirow[t]{2}{*}{2} & 0 & nd & nd & nd & nd & nd & nd \\
\hline & 0.5 & $0.45 \pm 0.03$ & $90.0 \pm 6.0$ & $0.58 \pm 0.01$ & $116 \pm 2.2$ & $0.61 \pm 0.06$ & $122 \pm 12$ \\
\hline \multicolumn{8}{|l|}{ River water } \\
\hline \multirow[t]{2}{*}{1} & 0 & nd & nd & nd & nd & nd & nd \\
\hline & 0.5 & $0.60 \pm 0.09$ & $120 \pm 18$ & $0.56 \pm 0.05$ & $111 \pm 10$ & $0.41 \pm 0.02$ & $82.2 \pm 4.0$ \\
\hline \multirow[t]{2}{*}{2} & 0 & nd & nd & nd & nd & nd & nd \\
\hline & 0.5 & $0.52 \pm 0.07$ & $104 \pm 14$ & $0.49 \pm 0.09$ & $97.6 \pm 18$ & $0.55 \pm 0.08$ & $109 \pm 16$ \\
\hline \multirow[t]{2}{*}{3} & 0 & nd & nd & nd & nd & nd & nd \\
\hline & 0.5 & $0.45 \pm 0.04$ & $90.4 \pm 8.0$ & $0.56 \pm 0.03$ & $112 \pm 6.1$ & $0.57 \pm 0.07$ & $113 \pm 14$ \\
\hline \multirow[t]{2}{*}{4} & 0 & nd & nd & nd & nd & nd & nd \\
\hline & 0.5 & $0.43 \pm 0.02$ & $86.4 \pm 4.1$ & $0.54 \pm 0.06$ & $108 \pm 12$ & $0.44 \pm 0.05$ & $88.4 \pm 10$ \\
\hline \multirow[t]{2}{*}{5} & 0 & nd & nd & nd & nd & nd & nd \\
\hline & 0.5 & $0.57 \pm 0.07$ & $114 \pm 14$ & $0.40 \pm 0.03$ & $80.4 \pm 6.0$ & $0.48 \pm 0.08$ & $96.2 \pm 16$ \\
\hline \multirow[t]{2}{*}{6} & 0 & nd & nd & nd & nd & nd & nd \\
\hline & 0.5 & $0.43 \pm 0.05$ & $85.8 \pm 10$ & $0.57 \pm 0.10$ & $114 \pm 20$ & $0.49 \pm 0.07$ & $98.1 \pm 14$ \\
\hline \multicolumn{8}{|l|}{ Effluent water } \\
\hline \multirow[t]{2}{*}{1} & 0 & nd & nd & nd & nd & nd & nd \\
\hline & 0.5 & $0.50 \pm 0.02$ & $100 \pm 3.9$ & $0.55 \pm 0.04$ & $109 \pm 7.8$ & $0.56 \pm 0.03$ & $113 \pm 6.2$ \\
\hline \multirow[t]{2}{*}{2} & 0 & nd & nd & nd & nd & nd & nd \\
\hline & 0.5 & $0.42 \pm 0.06$ & $84.7 \pm 12$ & $0.52 \pm 0.05$ & $104 \pm 10$ & $0.48 \pm 0.03$ & $95.8 \pm 5.6$ \\
\hline \multirow[t]{2}{*}{3} & 0 & nd & nd & nd & nd & nd & nd \\
\hline & 0.5 & $0.49 \pm 0.03$ & $98.0 \pm 5.9$ & $0.49 \pm 0.08$ & $98.2 \pm 16$ & $0.58 \pm 0.06$ & $116 \pm 12$ \\
\hline \multicolumn{8}{|l|}{ Influent water } \\
\hline \multirow[t]{2}{*}{1} & 0 & nd & nd & nd & nd & nd & nd \\
\hline & 0.5 & $0.55 \pm 0.02$ & $110 \pm 4.2$ & $0.54 \pm 0.05$ & $108 \pm 10$ & $0.57 \pm 0.05$ & $104 \pm 10$ \\
\hline \multirow[t]{2}{*}{2} & 0 & nd & nd & nd & nd & nd & nd \\
\hline & 0.5 & $0.51 \pm 0.06$ & $102 \pm 12$ & $0.48 \pm 0.09$ & $96.1 \pm 18$ & $0.44 \pm 0.08$ & $88.5 \pm 16$ \\
\hline \multirow[t]{2}{*}{3} & 0 & nd & nd & nd & nd & nd & nd \\
\hline & 0.5 & $0.49 \pm 0.04$ & $98.3 \pm 8.0$ & $0.46 \pm 0.11$ & $92.4 \pm 21$ & $0.52 \pm 0.04$ & $104 \pm 7.8$ \\
\hline
\end{tabular}

\footnotetext{
a Not detected.
} 
Table 5

Comparison of DPA concentrations in soil and sediment samples determined by IC-MS and LC-MS, and the relative errors (RE) between these two methods.

\begin{tabular}{|c|c|c|c|c|}
\hline Samples & Compounds & LC-MS $(\mu \mathrm{g} / \mathrm{kg})$ & IC-MS ( $\mu \mathrm{g} / \mathrm{kg})$ & $\mathrm{RE}(\%)$ \\
\hline \multirow{6}{*}{ Soil 1} & MEPA & 29.9 & 24.7 & 19 \\
\hline & DEPA & 16.7 & 20.8 & 21 \\
\hline & MHPA & 22.2 & 25.3 & 13 \\
\hline & AMEP & 1057.0 & 980.4 & 7.5 \\
\hline & ADEP & 473.8 & 504.9 & 6.4 \\
\hline & AMHP & 200.8 & 235.6 & 16 \\
\hline \multirow{6}{*}{ Soil 2} & MEPA & 16.8 & 13.5 & 22 \\
\hline & DEPA & 8.9 & 11.4 & 25 \\
\hline & MHPA & 27.2 & 32.7 & 18 \\
\hline & AMEP & 1728.0 & 1438.6 & 18 \\
\hline & ADEP & 999.1 & 843 & 17 \\
\hline & АMHP & 374.4 & 368.8 & 1.5 \\
\hline \multirow{6}{*}{ Sediment 1} & MEPA & $\mathrm{nd}^{\mathrm{a}}$ & nd & - \\
\hline & DEPA & nd & nd & - \\
\hline & MHPA & 106.6 & 89.7 & 17 \\
\hline & AMEP & 15.6 & 20.1 & 25 \\
\hline & ADEP & nd & nd & - \\
\hline & AMHP & 192.1 & 231.4 & 19 \\
\hline
\end{tabular}

a Not detected.

containing both anion-exchange group and a reversed-phase backbone, was selected as the SPE cartridge as it has been successfully used for the purification of DPAs in soils and sediments [8] and extraction of the hydrolysis of organophosphate esters flame retardant in human urine [27]. The loading $\mathrm{pH}$ was optimized in the first step. The test was performed by spiking $10 \mathrm{ng}$ of each of the analytes in $5 \mathrm{~mL}$ of influent water samples, which was pre-adjusted to $\mathrm{pH} 2,3,5,7,8$ and 9 with formic acid and $\mathrm{NH}_{3} \cdot \mathrm{H}_{2} \mathrm{O}$. Fig. 3 shows the effect of $\mathrm{pH}$ on the recovery of DPAs in influent water. Satisfied recoveries (94.0-113.2\%) were achieved for all the three DPAs at pH 5-9, whereas lower recoveries (17.3-62.9\%) were obtained for MEPA and DEPA at $\mathrm{pH} 2$ and 3. This can be ascribed to the fact that reversed-phase interaction was mainly responsible for the retention of DPAs on MAX sorbent at lower $\mathrm{pH}$, whereas ion-exchange retention became the dominant interaction at $\mathrm{pH}$ 5-9. Reversed-phase interaction, which was weaker than ion-exchange retention, was not sufficient for the retention of MEPA and DEPA for their short chain. Therefore, the $\mathrm{pH}$ of water samples should be adjusted to $\mathrm{pH}$ 5-9.

To evaluate the applicable maximum volume of sample solutions, we tested the breakthrough volumes of DPAs in SPE by using the relatively more polar MEPA and DPEA. Briefly, $50 \mathrm{~mL}$ of influent water of WWTP spiked with $500 \mathrm{ng}$ of each DPAs was passed through the MAX cartridge, and the eluent was collected in $1 \mathrm{~mL}$ fraction vials. The fractions were then analyzed directly by IC-MS, and the ratio between outlet and inlet $\left(A / A_{0}\right)$ was calculated to evaluate the breakthrough volume. Poole et al. recommended the breakthrough volume as the volume of sample that has passed through a sorbent bed until $1 \%$ of the analyte concentration is measured at the outlet [28]. With this judgment criteria, and based on the result shown in Fig. 4, the breakthrough volumes of MEPA and DPEA were determined to be $7 \mathrm{~mL}$ and $12 \mathrm{~mL}$, respectively. There was no observed MHPA in all the $50 \mathrm{~mL}$ of outlet. Therefore, fractions of $7 \mathrm{~mL}$ were collected for the SPE procedure.

\subsection{Method validation}

As shown in Table 1, the LODs and LOQs of the method were 1.2-3.1 $\mathrm{ng} / \mathrm{L}$ and 3.5-9.3 ng/L, respectively, for the determination of DPAs in different environmental water samples. The linear range of the method was $0.01-20 \mu \mathrm{g} / \mathrm{L}$ with the correlation coefficients $\left(R^{2}\right)$ of the matrix-fortified calibration curves all above 0.99 . The maximum signal suppression was $15.1 \%$, which was observed for MHPA in influent water samples, indicating the method was well acceptable regarding the matrix effect. The mean recoveries ranged from $75.8 \%$ to $110.2 \%$ with RSDs $\leq 20 \%$ were achieved (see Table 2), suggesting good precision and reproducibility of the proposed method. In addition, no carryover could be identified for all of the three compounds in the first blank sample after injection of highly concentration spiked influent samples.

For soil and sediment samples, LC-MS has been successfully used for monitoring the levels of ADPs and DPAs [8]. However, to uniform the method with water samples, the IC-MS was adapted to determine ADPs and DPAs in soil and sediment samples. As shown in Table 3, the matrix effects observed for soil and sediment samples extracted by $75 \mathrm{mM} \mathrm{NH}_{3} \cdot \mathrm{H}_{2} \mathrm{O}$ were $-4.2 \%, 4.0 \%$ and $24.6 \%$ for MEPA, DEPA, and MHPA respectively, and $1.8 \%, 8.3 \%$ and $10.6 \%$ respectively extracted by formic acid-water-methanol (5:5:90, v/v/v). The ion suppressions of MEPA were greatly improved by the using of IC-MS, compared with LC-MS ( $\sim 35 \%$ and $\sim 46 \%$ with $75 \mathrm{mM} \mathrm{NH}_{3} \cdot \mathrm{H}_{2} \mathrm{O}$, and formic acid-water-methanol $(5: 5: 90, v / v / v)$ as the extraction solvents, respectively). The linear range of the method for soil and sediment samples was $0.1-200 \mu \mathrm{g} / \mathrm{kg}$, with $R^{2}>0.99$ (Table 3 ). The LOQ and LOD for soil and sediment samples were $0.06-0.09 \mu \mathrm{g} / \mathrm{kg}$ and $0.02-0.03 \mu \mathrm{g} / \mathrm{kg}$, which was greatly improved comparing with LC-MS $(0.92-1.0 \mu \mathrm{g} / \mathrm{kg}$ and $0.31-0.33 \mu \mathrm{g} / \mathrm{kg}$, respectively).

The IC-MS chromatograms of DPAs in environmental water and soil samples extracted by $75 \mathrm{mM} \mathrm{NH} \cdot \mathrm{H}_{2} \mathrm{O}$ were shown in Fig. 5 , in which peak broadening was observed for environmental water samples. The peak broadening might be attributed to the coextraction of substances that could influence the retention behavior of analytes in the AS11-HC column. Nevertheless, peak broadening has a limited influence on the quantification as peak area, used for quantification in this study, was not significantly changed for different sample matrices. In addition, although the maximum matrix effect observed for different water samples was $15.1 \%$ (Table 1 ), matrix-fortified calibration curves instead of neat standard curves were used for the calibration. Moreover, for the 14 different blank water samples spiked with $0.5 \mu \mathrm{g} / \mathrm{L}$ DPAs, the recoveries determined by the proposed method were in the range of $80.4-122.0 \%$, demonstrating the feasibility of the proposed method.

\subsection{Method application}

The proposed method was applied to the analysis of DPAs in tap water, river water, influent and effluent water of WWTPs. For all the 14 samples analyzed, the DPAs contents were below LODs without exception. Therefore, the recoveries of the 14 samples 

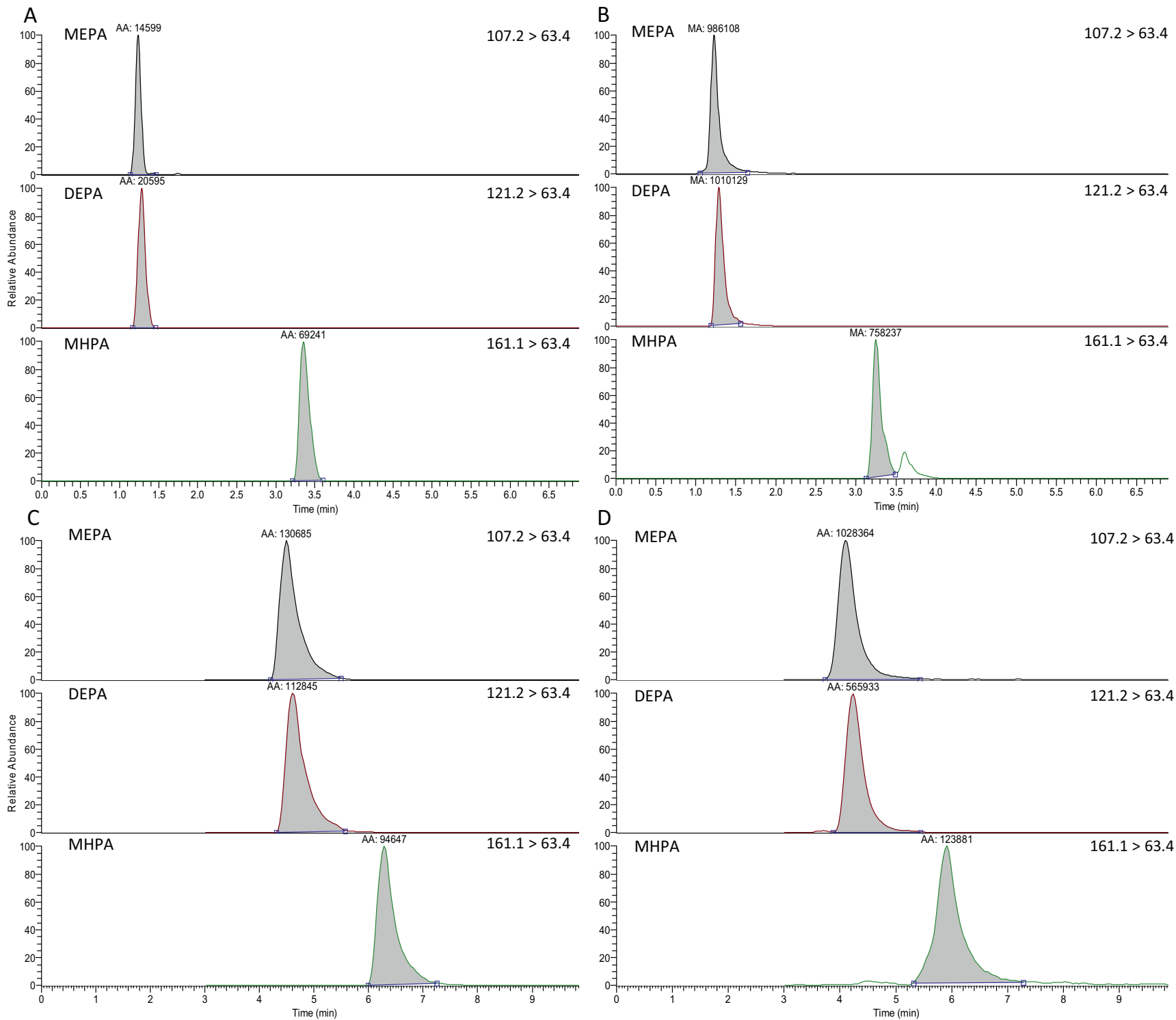

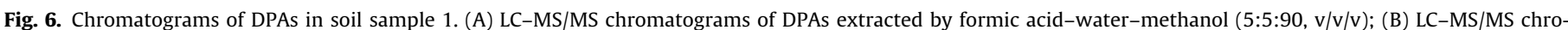

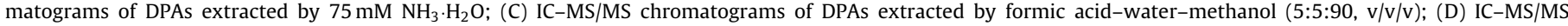
chromatograms of DPAs extracted by $75 \mathrm{mM} \mathrm{NH}_{3} \cdot \mathrm{H}_{2} \mathrm{O}$ and diluted by a factor of 10 .

mentioned above were determined at $0.5 \mu \mathrm{g} / \mathrm{L}$ spiking levels. As shown in Table 4, the recoveries were in the range of $80.4-122.0 \%$, demonstrating the feasibility of the proposed method.

In addition, the proposed method was applied to three soil and sediment samples randomly selected from the samples detected in our previous study [8]. The results in Table 5 demonstrated that the measurements agreed well with the results determined by LC-MS. The relative error (RE) between the two results was less than $25 \%$. Fig. 6 shows the LC-MS and IC-MS chromatograms of soil sample 1 .

\section{Conclusions}

Coupling SPE cleanup with IC-ESI-MS/MS detection, a novel procedure was developed for identification and quantification of DPAs in various environmental samples including water, soil and sediment samples. By integrating SPE preconcentration and cleanup, large volume sample injection, as well as introducing $\mathrm{NH}_{3} \cdot \mathrm{H}_{2} \mathrm{O}$ and methanol into the MS system to promote the ionization of DPAs in the ESI process, the proposed method showed excellent selectivity and sensitivity. Unlike the coupling of SPE with LC-ESI-MS/MS which was not applicable for the analysis of DPAs in environmental water samples for their strong polarity, this proposed method has been applied successfully to analyze environmental water, soil and sediment samples.

\section{Acknowledgements}

This study was financially supported by the High-Tech Research and Development Program of China (2013AA065201), the National Natural Science Foundation of China (21321004), and Chinese Academy of Sciences (YSW2013A01, YSW2013B01).

\section{References}

[1] I. Meerts, R.J. Letcher, S. Hoving, G. Marsh, A. Bergman, J.G. Lemmen, B. van der Burg, A. Brouwer, In vitro estrogenicity of polybrominated diphenyl ethers hydroxylated PBDEs, and polybrominated bisphenol A compounds, Environ. Health Perspect. 109 (2001) 399-407.

[2] A. Schecter, O. Papke, K.C. Tung, J. Joseph, T.R. Harris, J. Dahlgren, Polybrominated diphenyl ether flame retardants in the US population: current levels, 
temporal trends, and comparison with dioxins, dibenzofurans, and polychlorinated biphenyls, J. Occup. Environ. Med. 47 (2005) 199-211.

[3] F. Fonnum, E. Mariussen, Mechanisms involved in the neurotoxic effects of environmental toxicants such as polychlorinated biphenyls and brominated flame retardants, J. Neurochem. 111 (2009) 1327-1347.

[4] T. Schreiber, K. Gassmann, C. Goetz, U. Huebenthal, M. Moors, G. Krause, H.F. Merk, N.-H. Nguyen, T.S. Scanlan, J. Abel, C.R. Rose, E. Fritsche, Polybrominated diphenyl ethers induce developmental neurotoxicity in a human in vitro model: evidence for endocrine disruption, Environ. Health Perspect. 118 (2010) $572-578$.

[5] I. van der Veen, J. de Boer, Phosphorus flame retardants: properties, production, environmental occurrence, toxicity and analysis, Chemosphere 88 (2012) 1119-1153.

[6] E. Schmitt, Phosphorus-based flame retardants for thermoplastics, Plastics Addit. Compd. 9 (2007) 26-30.

[7] Australian Government Regulator of Industrial Chemicals, Chemical in Exolit OP 1312, in: Australian Department of Health and Ageing (administration)(Ed.), National Industrial Chemicals Notification and Assessment Scheme NICNASFull Public Reports, 2005.

[8] Y. Niu, J. Liu, Y. Liang, Z. Hao, J. Liu, Y. Liu, X. Sun, Aluminum dialkyl phosphinate flame retardants and their hydrolysates: analytical method and occurrence in soil and sediment samples from a manufacturing site, Environ. Sci. Technol. 48 (2014) 3336-3343.

[9] S. Waaijers, D. Kong, H. Hendriks, C. Wit, I. Cousins, R.S. Westerink, P.G. Leonards, M.S. Kraak, W. Admiraal, P. Voogt, J. Parsons, in: D.M. Whitacre (Ed.), Reviews of Environmental Contamination and Toxicology, Springer, New York, 2013, pp. 1-71.

[10] G.G. Briggs, Theoretical and experimental relationships between soil adsorption, octanol-water partition coefficients, water solubilities, bioconcentration factors, and the parachor, J. Agric. Food Chem. 29 (1981) 1050-1059.

[11] S.L. Waaijers, T.E. Bleyenberg, A. Dits, M. Schoorl, J. Schütt, S.A.E. Kools, P. de Voogt, W. Admiraal, J.R. Parsons, M.H.S. Kraak, Daphnid life cycle responses to new generation flame retardants, Environ. Sci. Technol. 47 (2013) 13798-13803.

[12] B.K. Matuszewski, M.L. Constanzer, C.M. Chavez-Eng, Strategies for the assessment of matrix effect in quantitative bioanalytical methods based on HPLC-MS/MS, Anal. Chem. 75 (2003) 3019-3030.

[13] D.M. Mueller, B. Duretz, F.A. Espourteille, K.M. Rentsch, Development of a fully automated toxicological LC-MS(n) screening system in urine using online extraction with turbulent flow chromatography, Anal. Bioanal. Chem. 400 (2011) 89-100.

[14] M. Liu, Y. Hashi, Y. Song, J.-M. Lin, Simultaneous determination of carbamate and organophosphorus pesticides in fruits and vegetables by liquid chromatography-mass spectrometry, J. Chromatogr. A 1097 (2005) 183-187.
[15] C. Jansson, T. Pihlström, B.-G. Österdahl, K.E. Markides, A new multi-residue method for analysis of pesticide residues in fruit and vegetables using liquid chromatography with tandem mass spectrometric detection, J. Chromatogr. A 1023 (2004) 93-104.

[16] L. Meng, S. Wu, F. Ma, A. Jia, J. Hu, Trace determination of nine haloacetic acids in drinking water by liquid chromatography-electrospray tandem mass spectrometry, J. Chromatogr. A 1217 (2010) 4873-4876.

[17] S.R. Dahl, K.M. Olsen, D.H. Strand, Determination of gamma-hydroxybutyrate (GHB), beta-hydroxybutyrate (BHB), pregabalin, 1,4-butane-diol (1,4BD) and gamma-butyrolactone (GBL) in whole blood and urine samples by UPLC-MSMS, J. Chromatogr. B 885-886 (2012) 37-42.

[18] L. Novakova, T. Gottvald, H. Vickova, F. Trejtnar, J. Mandikova, P. Solich, Highly sensitive fast determination of entecavir in rat urine by means of hydrophilic interaction chromatography-ultra-high-performance liquid chromatographytandem mass spectrometry, J. Chromatogr. A 1259 (2012) 237-243.

[19] K.-H. Bauer, T.P. Knepper, A. Maes, V. Schatz, M. Voihsel, Analysis of polar organic micropollutants in water with ion chromatography-electrospray mass spectrometry, J. Chromatogr. A 837 (1999) 117-128.

[20] L. Huang, D. Yang, X. Guo, Z. Chen, Speciation analysis of inorganic tin by oncolumn complexation ion chromatography with inductively coupled plasma mass spectrometry and electrospray mass spectrometry, J. Chromatogr. A 1368 (2014) 217-221.

[21] T.P. Knepper, A. Werner, G. Bogenschütz, Determination of synthetic chelating agents in surface and waste water by ion chromatography-mass spectrometry, J. Chromatogr. A 1085 (2005) 240-246.

[22] M.L. Trehy, J.C. Reepmeyer, R.E. Kolinski, B.J. Westenberger, L.F. Buhse, Analysis of heparin sodium by SAX/HPLC for contaminants and impurities, J. Pharm. Biomed. 49 (2009) 670-673.

[23] R. Kostiainen, T.J. Kauppila, Effect of eluent on the ionization process in liquid chromatography-mass spectrometry, J. Chromatogr. A 1216 (2009) 685-699.

[24] R. Mol, G.J. de Jong, G.W. Somsen, Atmospheric pressure photoionization for enhanced compatibility in on-line micellar electrokinetic chromatography-mass spectrometry, Anal. Chem. 77 (2005) 5277-5282.

[25] S. Zhou, M. Hamburger, Effects of solvent composition on molecular ion response in electrospray mass spectrometry: investigation of the ionization processes, Rapid Commun. Mass Spectrom. 9 (1995) 1516-1521.

[26] F. Gosetti, E. Mazzucco, D. Zampieri, M.C. Gennaro, Signal suppression/enhancement in high-performance liquid chromatography tandem mass spectrometry, J. Chromatogr. A 1217 (2010) 3929-3937.

[27] K. Möller, C. Crescenzi, U. Nilsson, Determination of a flame retardant hydrolysis product in human urine by SPE and LC-MS. Comparison of molecularly imprinted solid-phase extraction with a mixed-mode anion exchanger, Anal. Bioanal. Chem. 378 (2004) 197-204.

[28] C.F. Poole, A.D. Gunatilleka, R. Sethuraman, Contributions of theory to method development in solid-phase extraction, J. Chromatogr. A 885 (2000) 17-39. 